\title{
Analysis on the Theory and Practice of Petroleum Exploration Geology in Ordos Basin
}

\author{
Zhenhua Li, Suya Zhang \\ College of Energy Engineering of Longdong University, Gansu, Qingyang, 745000
}

Keywords: Ordos Basin; petroleum exploration; Triassic Yanchang Formation

\begin{abstract}
The Ordos Basin is a large inland depression basin. The basin is surrounded by highland denudation zones. The water system extends to the lake basin, forming multiple sets of river-lake phase terrigenous clastic sediments. The lithofacies belt is alluvial from the edge of the basin to the interior of the basin. Phase, braided river, braided river giant angle continent and lake phase, the upper phase of the plane is obviously ring-shaped, and the asymmetry is distributed around the deep lake area. Because the northern terrain is flat, the phase belt is wide, and the southern part is steep due to the topography. The belt is narrower. The Upper Triassic Yanchang Formation in the Mesozoic in the Ordos Basin is rich in petroleum resources. With the continuous development of exploration technology, the average annual growth rate of proven petroleum reserves and oil production in the Ordos Basin is far ahead of other major basins, exploration and development. The potential is huge. The paper mainly discusses the theoretical and practical issues of petroleum exploration geology in the Ordos Basin.
\end{abstract}

\section{Overview}

The Ordos Basin is a large-scale intracontinental superimposed basin on the base of the Paleozoic craton shallow sea platform in the Mesozoic and Cenozoic basins. It is located at the intersection of several tectonic stress fields, and the stresses are mutually reduced and balanced, and the internal structure is relatively stable. It has developed seven major tectonic units such as the Jinxi Tangle Belt, the Yishan Slope, the Tianhuan Depression, the Western Edge thrust belt, the Weibei Uplift and the Yimeng Uplift. The oil and gas fields discovered today are mainly distributed in the Yishan Slope and the Tianhuan Depression. The Mesozoic in the Ordos Basin is a typical large inland depression basin with stable sedimentation, wide basin and large sedimentary range. In the early Late Triassic, it entered the lake basin development stage and developed a river-delta facies-lake. Phase clastic rock deposits, due to the abundant supply of resources, coupled with the stable return of the lake basin, deposited a set of lake-delta fractal rocks with a thickness of about 1,000 meters. The reservoirs of the Triassic Yanchang Formation are mainly controlled by high-quality source rocks and large-scale reservoir sand bodies. By continuously summarizing and deepening the reservoir-forming characteristics of low-permeability lithologic reservoirs, the model of the main development of the meandering river delta is prolonged. The model of the Meandering River Delta is: the sedimentary system in the northeast of the basin is the Meliuhe delta deposit, the reservoir is distributed along the main sand belt of the front of the meandering river delta, and the underwater distributary channel sand body is the main reservoir. Oilfield and Jing'an Oilfield are represented. The braided river delta is a model of reservoir formation: the sedimentary system in the western part of the basin is a braided river delta deposit, and the reservoir is controlled by the sand body of the braided river delta front, which is distributed in a strip shape, represented by the East-Western Mine. Multi-layered composite accumulation model: the northwestern part of the basin is located in the hydrocarbon-generating center. The thickness of the source rock is large, and the reservoir sand body develops vertically. Under the effective combination of abnormal pressure and various transport systems, the vertical layer is formed. The scene of compound oily is represented by Jiyuan Oilfield. The reservoir formation model in the central part of the depression: the reservoir is mainly controlled by the delta front and the gravity-flow composite sedimentary sand body, showing a large area distribution, represented by Huaqing Oilfield. Tight oil 
accumulation mode: source and reservoir interbeds are symbiotic, stacked vertically and horizontally, and the reserves are large, which is represented by the extension of the group 7 oil layer.

The characteristics of oil and gas exploration in the Ordos Basin are mainly reflected in the following aspects: First, the resources are large and have broad prospects for exploration and development; secondly, the oil and gas area is large and the reserves are low; third, the reservoir is dense and the porosity is $4 \%-15 \%$, the permeability is $(0.1-1) * 10-3 \mu \mathrm{m} 2$; fourthly, the large lithologic trap is the main trap type, which is relatively concealed; fifth, the natural productivity of the oil and gas layer is low, and it needs to be stored. On the whole, oil and gas development in the Ordos Basin reflects the near-source accumulation of "full basin and semi-potential oil", which is characterized by large-area ultra-low permeability lithologic reservoirs. Improving the economics and effectiveness of oil and gas exploration and development in the Ordos Basin has always been the primary problem restricting oil development in the Ordos Basin. The oil well has low natural production capacity or no natural production capacity. It must be fracturing and reforming. The natural productivity of the well is low or there is no natural production capacity. The fracturing transformation must be carried out. The average daily output of the oil well is $2-4 \mathrm{t}$. At the same time, the "three low" oilfields in Changqing Oilfield have the following eight advantages: moderate burial; large area, stable reservoir distribution; low crude oil and good fluidity; reservoir rocks are mainly acid-sensitive minerals, and water-sensitive minerals are less. It is conducive to water flooding development; reservoir wettability is weak hydrophilic-neutral layer; more movable oil, good displacement efficiency; reservoir micro-crack development, strong water absorption capacity; reservoir pores, micro-cracks better, can form a good seepage condition.

\section{Exploration Theory and Practice}

\subsection{Current Status of Exploration in Ordos Basin.}

To objectively understand and grasp the current situation of the petroleum resources of the Upper Triassic Yanchang Formation in the Ordos Basin, we must also pay attention to the following two facts. (1) In the past oil and gas resources evaluation, only the hydrocarbon generation of high-quality source rocks (high-resistance oil shale) in the Chang 7 oil-bearing formation of the Yanchang Formation was calculated. In fact, except for the Chang 7 oil-bearing formation group, the length of the extended group is 9 The upper part of the oil layer group-the Chang 8 oil layer group and the Chang 7 oil layer group upper - the long (4+5) oil layer group are all developed with good quality source rocks. Taking the Chang 9 oil layer group as an example, the recent drilling and organic geochemical tests and researches show that the average TOC content of the lacustrine source rocks in the upper section of the Chang 9 oil layer group is $5.03 \%$, and the average asphalt "A" content is $0.8603 \%$. The organic parent material The type is a saprolite type with low aquatic organisms as the main source, and has reached the stage of thermal evolution of the peak of oil production. The Zhidan-Ganquan-Huangling area in the southeastern part of the basin is the main development area of the Chang 9 source rock. The dark mudstone + oil shale has a thickness of $2-20 \mathrm{~m}$ and a distribution area of $1.6 \times 104 \mathrm{~km} 2$. The average hydrocarbon generation potential of this source rock is $15.94 \mathrm{~g} / \mathrm{cm} \mathrm{3}$, and the preliminary hydrocarbon generation can reach $50 \times 108 \mathrm{t}$. (2) The reservoir types of the Upper Triassic Yanchang Formation in the Ordos Basin are mainly lithologic reservoirs with low abundance, large area but poor lateral continuity. The calculated values of resources and exploration technology level, exploration degree and geological understanding the degree and the like have a close relationship. From the previous two assessments to the third assessment, the most important reason for the increase in resource resources is the improvement of exploration level, the improvement of resource evaluation methods, the advancement of exploration technology and the understanding of geological laws of oil and gas accumulation. From the analysis of the degree of proven reserves, the proven extent of mature exploration zones in similar basins at home and abroad is generally $50 \%$ to $60 \%$, while the exploration is conservatively estimated in the case where the exploration level is relatively low and 
is at the peak of reserve growth. The degree of visibility can reach more than $70 \%$, which is most likely caused by the low calculation of resources. The investment in exploration work in the Ordos Basin has been greatly increased, which has promoted the innovation and development of geological understandings such as sediments, reservoirs, source rocks and reservoir-forming laws. At the same time, it is suitable for seismic acquisition and treatment of geological features of the Ordos Basin, and low-resistance oil and gas. Oil and gas exploration supporting technologies such as comprehensive logging identification and fracturing reform of low-permeability oil and gas layers have also made great progress, and it is necessary to re-recognize and evaluate the amount of oil resources and their distribution.

\subsection{Distribution Characteristics of the Proven Resources of the Triassic Yanchang Formation.}

Plane distribution characteristics: During the depositional period of the Upper Triassic Yanchang Formation, the Ordos Basin developed a provenance system with four directions: northeast, northwest, southwest and southeast. Correspondingly, it formed from the edge of the basin to the center of the lake basin. Rivers - (Shadow River) Delta - Lake sedimentary system. The results of many years of exploration and development have shown that the submerged distributary channel sand bodies, the estuary dam sand bodies and the turbidite fan sand bodies in the middle of the lake basin in the delta front of each sedimentary system are the most important oil sands in the Yanchang Formation. Body [7], that is, each deposition system basically corresponds to a set of oil-containing systems. Therefore, the distribution of the amount of resources to be proved on the plane can be analyzed according to the average superposition distribution range of different oil layer groups of each deposition system, and it is preferable to find a favorable deposition system for large and medium oil fields. Longitudinal distribution characteristics: The extended group can be further divided into upper (length 1 - length 3), middle (length 4 - length 8) and lower (length 9 - length 10) 3 sets of oil-containing combinations in the longitudinal direction. Among them, the resource content of the upper oil-bearing combination is $20.64 \times 108 \mathrm{t}$, the amount of resources to be proved is $17.6 \times 108 \mathrm{t}$, accounting for $33.5 \%$ of the resources to be proved in the extended group; the combined resources of the middle-lower group is $50.32 \times 108 \mathrm{t}$, and the amount of resources to be proved is 39.6. $\times 108$ t, accounting for $66.5 \%$ of the total amount of resources to be prolonged in the extended group. It can be seen that the middle-lower combination of the Upper Triassic Yanchang Formation is the main place for the exploration of the Mesozoic resources, and is the main exploration area for the Ordos Basin to continue to search for large and medium-sized oilfields.

\section{Prospects and Experience of Petroleum Exploration in Ordos Basin}

With the continuous advancement of exploration technology, the oil reserves and production in the Ordos Basin have been greatly improved, and have entered a period of stable growth. In the follow-up, the oil exploration of the Yanchang Formation can be divided into two levels to ensure that its reserves will continue to grow steadily within 5-10. On the one hand, the central, northwest, and southwestern systems of the lake basin are the real areas for the recent increase in reserves and production. On the one hand, the northeast system and the northwest system can be used as the main areas for exploration replacement in the next 5-10 years. Because of the large amount of resources to be discovered in the area, the reserves can continue to grow. The Changqing Oilfield located in the Ordos Basin is mainly for the practice of low-permeability lithologic reservoirs. In order to continuously update and deepen the petroleum exploration geological theory and practice system in the Ordos Basin, it is necessary to continuously improve the theoretical system of petroleum exploration, with the advancement of science and technology. And the researchers continue to sum up experience in actual exploration, and have made many advances, such as multi-layer petroleum enrichment rules, large delta sedimentary models, and storage characteristics of special reservoirs, so that oil exploration technology has been continuously developed. China's oil exploitation has made a huge contribution. In addition, the northern part of Shaanxi is mainly located in the eastern part of the Ordos Basin. The structure here is very gentle, the climate is relatively humid, the rain is abundant, and the water source is abundant. The main reason is that 
many rivers have developed here, and local products have been created in this environment. The resources are relatively abundant, the sediments in the basin are relatively serious, and it also provides a powerful condition for the formation of many large deltas. Through the actual exploration of the researchers, the law of finding oil-rich areas through the delta is summarized, and the basics of finding oil through the delta are Based on the theoretical basis and comprehensive analysis of the law of basin formation, it was found that the oil reserves in northern Shaanxi are very large, which has made great contributions to China's petroleum industry.

\section{References}

[1] Chen Wuquan, Chen Fengling. Sedimentary characteristics and petroleum exploration direction of the Yanchang Formation in the northern part of the Ordos Basin [J].Petroleum Geology and Engineering, 2008, 22(4):10-13.

[2] Chen Wuquan. Sedimentary characteristics and oil layer distribution of deep-water sand bodies of Yanchang Formation in Weibei area, Ordos Basin [J].Petroleum Geology and Engineering, 2009, 23(4):16-19.

[3] Yang Youyun. Sedimentary systems and sequence characteristics of Yanchang Formation in the southern Ordos Basin [J].Geologcal Bulletin OF China, 2005,24(4):369-372.

[4] Wang Jufeng, Guo Yanru, Zhang Yanling, et al. Sequence stratigraphic framework and sedimentary facies of the Triassic Yanchang Formation in the Ordos Basin[J]. 现代地质, 2009, 23(5): 803-808.

[5] NI Xinfeng, CHEN Hongde, WEI Dongxiao. Sequence stratigraphic framework and oil and gas exploration of the Triassic Yanchang Formation in the Ordos Basin[J]. Chinese Geology, 2007, 34(1): 73-79.

[6] Zhang Wenzheng, Ordos Basin, Hua, Fu Suantang, et al. Developmental mechanism of high-quality source rocks in the Chang 91 lacustrine facies in the Ordos Basin[J]. Chinese Science: D, 2007, 37 (Supplement): 33-38.

[7] ZHAO Junxing, LI Fengjie, SHEN Xiaoli, et al. Sedimentary characteristics and developmental patterns of turbidite events in the Chang 6 and Chang 7 oil layers in the southern Ordos Basin[J].Acta Petrolei Sinica, 2008, 29(3): 389-394.

[8] LIU Xiaoqi, DENG Hongwen, LI Qingbin, et al. Residual pressure distribution and hydrocarbon migration and accumulation conditions in the Yanchang Formation of the Ordos Basin[J].Xinjiang Petroleum Geology, 2007,28(2):143-145.

[9] ZHAO Wenzhi,WANG Xinmin,GUO Yanru, et al.Recovery and evolution of the Late Triassic prototype basin in the western Ordos Basin[J].Petroleum Exploration and Development, 2006,33(1):6-13.

[10] Zhao Jingzhou, County Super, Ordos Basin, Wu Fuli, et al. Controlling the formation and distribution of Triassic reservoirs in the northern slope of the Ordos Basin in the Ordos Basin[J]. Journal of Geology, 2006, 80(5): 648-655. 